\title{
EL ESCRIBIDOR INTRUSO; ARTÍCULOS, CRÓNICAS Y ENTREVISTAS
}

(FRAGMENTO)

José Donoso (1960)

\section{A LA BÚSQUEDA DE LOS PUEBLOS DESAPARECIDOS}

Durante seis días recorrí la zona devastada por la catástrofe, desde Concepción a Ancud, llegando hasta Liqueñe, vallecito perdido en la cordillera de Valdivia, que debido a más de sesenta derrumbes, quedó aislado de la civilización. Fue allí, en los ojos opacos de dolor del colono Juan Antonio Luengo, que perdió casa y familia, donde me di cuenta de la magnitud del cataclismo. En Liqueñe, estuve en presencia del fenómeno telúrico mismo, lo vi, lo palpé, caminé por él, y se me hizo imposible comprender otra cosa que el terror de la catástrofe.

Al partir de Santiago en avión, un pequeño monomotor de dos plazas, fui descubriendo mi país, que me era desconocido. A medida que avanzaba hacia el sur, la emoción que se apretaba en mi pecho, me iba repitiendo: "Chile es el país más hermoso del mundo, el más hermoso de todos". Las montañas blancas, arrebozada en sus pañuelos de niebla: el esplendor de los lagos manchados de sombra, de nubes y de oro del sol; los manzanares, los bosques de coigües, de robles amarillos, de pinos plantados por los hombres en ordenados cuadriláteros; los innumerables ríos trazando sus curvas ricamente moduladas a través de los campos donde, aun en tiempo de tragedia, los pobladores aran y recolectan, todo me hacía repetirme desde el aire: "Sí, sí. Chile es el país más hermoso del mundo".

Pero al aterrizar, en todas partes surgía la tragedia, borrando cualquier recuerdo de belleza. Los rostros desolados. El ir y venir de la actividad impotente. Los seres desplazados de sus centros que deben buscar una vida nueva, un orden nuevo, si les queda energía. Cada aterrizaje, era descender en el centro mismo del dolor, y recibir el bofetón en pleno rostro. No obstante, no vi terror sino en ciertos sectores. El pillaje es escaso. Los heridos están atendidos. Las industrias claves no sufrieron daños irreparables. Es el particular, el pequeño hombre que busca su vida solo y por su propio esfuerzo el que sufrió más. Es el dueño de una tienda de pueblo, el propietario de un restaurante, de una paquetería, de una mínima industria lechera, levantada con inmenso sacrificio; el empleado, que por fin logró construir su casa o adquirir sus muebles; el que ahorró para comprar un vaca, una radio, una cama, una olla. 


\section{Las monjas Sacramentinas de Concepción}

Lo más sorprendente que me tocó vivir en Concepción, fue mi visita al convento de las monjas Sacramentinas, religiosas de clausura, dedicadas a la adoración. Jamás hablan, y antes de este terremoto, nunca habían salido a la calle. La catástrofe rompió la clausura hasta que la situación se normalice, y algunas de ellas tuvieron que buscar refugio fuera del convento.

Incluso en tiempos normales, las Sacramentinas viven en voluntaria pobreza, comiendo sólo lo suficiente para conservar la salud, durmiendo con camastros en cuartos alrededor de mínimos patios ahogadores. No poseen otro lujo que su amor a Dios. Pero el despojamiento de las Sacramentinas de Concepción no es la pobreza estética y limpia de monjas de clausura como las Carmelitas de los grandes conventos europeos, sino una clausura pavorosamente pobre, sombría, sin otra luz que la del alma. El terremoto las despojó aún de esta misérrima vida. La capilla se desplomó. Las celdas quedaron inhabitables, y entre los escombros las vi trabajar con pala y pico, arrastrando grandes piedras, dobladas bajo el peso de baúles, de santos, de sillas y mesas. Al verme, algunas se escabulleron como animales asustados entre las pilas de mampostería arruinada. Sin embargo, hablé con la superiora, una italiana de unos cincuenta años, de hermoso rostro sereno, modales llenos de nobleza, que me mostró lo que quedaba de la capilla y del convento.

-Estábamos en el oratorio cuando comenzó el terremoto -me dijo-. No hubo pánico, aunque sí, deseo de salvar nuestras vidas como Dios manda. Salimos rezando hasta la huerta.

La congregación consiste en once religiosas, tres italianas, dos mexicanas, y el resto chilenas. Sólo una de ellas sufrió, una moja chilena de noventa años, que tuvo que ser llevada al hospital de niños.

Había pasado varios terremotos en Concepción, pero sólo ahora, por primera vez, después de sesenta años, abandonaba la clausura. La visité en el hospital. Estaba sin conocimiento, víctima de shock nervioso. Entre las sábanas blancas, su rostro rugoso era como un terrón, como un pedazo de escombro, de los que llenan las calles de Concepción. La mayoría de las monjas se negaron a abandonar la clausura, pese al peligro de que el convento, perdonado por otros terremotos, caiga sobre sus cabezas.

A pesar que Temuco sufrió poco más que el derrumbamiento de algunos muros viejos, las noticias que llegaban de la costa y del interior sobrecogían al pueblo entero. Toltén, arrasado por el mar. Puerto Saavedra borrado del mapa. Inmensos cataclismos, todavía conocido sólo por rumores, en la región del lago Calafquén. Valdivia destrozada y sin comunicaciones. El Intendente, Oscar Schleyer, sobrevoló 
las regiones devastadas, pero debido al mal tiempo y a la falta de pistas no pudo aterrizar. Además, debía permanecer en Temuco, ya que esa ciudad es el centro de la ayuda a Valdivia y a las regiones de la costa. Toda la población de Temuco se movilizó. Prestaron autos, regalaron ropa y víveres, facilitaron casas. Desde el primer momento se despacharon a las regiones de la costa camiones del Ejército y de particulares con ropa, alimentos, y remedios. Manifesté mi deseo al Intendente de ir a Toltén, y a las cinco de la mañana del día siguiente, acompañado por Ugarte, fotógrafo del Diario Austral, partí en una camioneta particular que llevaba alimentos.

\section{Toltén: la traición del mar}

Llegamos a Toltén -a lo que queda de Toltén- a las ocho de la mañana. Fue mi primera visión auténtica de la tragedia. Esta era la llaga misma, geológica y humana, manando sangre. El terror igualaba todos los rostros. Ocho cadáveres verdes e hinchados, junto al camino. La tierra agrietada, y el agua revuelta y el cielo negro de llovizna, y el miedo atropellando la palabra en las bocas de todos.

Yo conocía Toltén. Había estado allí, hacía muchos años, en un claro día de verano pródigo de sol y de cosechas, bullente de paz activa. Los pescadores en la barra tendiendo sus redes al sol, el río manso, el mar benigno, las calles limpias, separando las casas de agricultores contentos y de modestos comerciantes. No quedaba ni un rastro de ese día. Aunque en Toltén todavía hay algunas casas, ni una está intacta. Unas, abiertas como bocas agonizantes, muestran en su interior un juguete de niño, un pan abandonado sobre un plato.

Los comercios partidos en dos, muestran sus tristes mercancías colgadas de las vigas: ollas, zapatos, trajes, rollos de cuerda, estilando aún en el agua de la marea. Otras, sin fachada, con los tablones plateados por el mar salino estirados como brazos. Colchones, sillas, teteras en las ramas de los árboles. Algunas casas fueron arrastradas cinco cuadras por la ola. Vi un bote incrustado en una tienda a ocho cuadras del mar.

En el pueblo, ni un alma. Todo en silencio. Sólo el graznido de las gaviotas circundando impertérritas. De pronto, de entre los escombros, surgió un hombre cargado con una máquina de coser de pie. Pasó junto a mí corriendo hacia tierra firme. Le hablé, pero no me vio ni me oyó. Más allá, una mujer siguiendo a una mula cargada, con sus humildes pertenencias. Les hablé, pero no me vieron, cegados por su afán de huir.

En una casa que fue arrancada de su sitio, pero que estaba en pie, encontré a un hombre y a sus hijos que recogían sus cosas para huir. 
Armando Holzapfel Azócar, de 49 años, nacido y criado en Toltén, dueño de 40 hectáreas. Quería contar las cosas, pero entre su deseo de huir y de hablar se atropellaba con los muebles de su casa:

-Toltén no tenía por qué estar aquí, bajo el nivel del mar, sino al otro lado del río, en un alto, donde el pueblo está trazado desde hace años junto a la estación del ferrocarril. Es el descuido de los parlamentarios. Todos estábamos dispuestos a trasladarnos para allá. El tren es inservible, porque tenemos que atravesar el río en balsa para llegar a él. Todos tenemos sitios al otro lado. Los parlamentarios son los que tienen la culpa... sí, señor, los parlamentarios.

\section{Los aislados}

Seguí caminando por el pueblo. Sólo destrucción y soledad. Más allá vino a mi encuentro un carabinero que corría y me dijo que saliera pronto de Toltén, porque la marea estaba subiendo. El carabinero Poblete, que apenas lograba hablar de temor, dijo que él no presenció el maremoto, porque su señora estaba "enferma de parto" en Temuco. Ese niño, nacido el 21 de mayo, les había salvado la vida.

- ¿Ve esos pinos? -me preguntó mientras corríamos-. Salvaron a mucha gente, que se subió a ellos cuando vieron la marea que crecía. En el intervalo de las dos olas, un muchacho que se llamada Sáenz se acercó con su camión a los pinos para llevar a la gente a tierra firme. Pero la segunda ola lo barrió con camión y todo, y Sáenz murió como un héroe.

Los carabineros dijeron que lo más trágico del maremoto era que la gente había huido a los cerros y mucha se encontraba todavía allí, aislada y sin víveres. Los del cerro Nilhue no podían salir porque había quedado convertido en isla. El resto de la población, fuera de los ya trasladados a Temuco, estaban refugiados en Villa Boldos, unos cuantos kilómetros al interior.

Villa Boldos, sólo una calle con treintena de casas de madera, era habitada por sonámbulos, gente sin expresión ni lágrimas, parada, sin hablar, aguardando algo; no sabían qué. Le pregunté a una mujer con un niño en brazos si quería irse con nosotros a Temuco. Respondió:

-No, no me voy hasta que no aparezca Él.

De vuelta a Temuco sobrevolé Puerto Saavedra. Fue imposible aterrizar por falta de pista. Para mí fue lo más angustioso de todo hasta el momento, porque conocía bien el pueblo y a su gente. Pasé un verano luminoso, alojado en casa de unos pescadores, los Leal, que vivían en la barra. Con Mingo Leal recorrí toda la zona a caballo, y Licha, su hermana, me tejió un chaleco con la lana de una oveja suya, que ella misma hiló en su huso. 
De la casa de los Leal, en la barra, no quedaba ni rastro. En realidad, la barra había desaparecido y se formó otra más afuera. No quedaba nada de nada. ¿Dónde estaba el bar de Benty Bogan, el loco marinero yugoslavo que se quedó en Puerto Saavedra porque se casó con una india de religión? ¿Y el rancho de la inglesa bautista, que todo el pueblo creía loca, porque a pesar de no tener ni para comer ella, compraba buena carne para su quiltro? ¿Y el almacén del turco de enormes bigotes, con quien me sentaba entre los barriles de yerba mate y de arvejas secas a charlar largas horas? ¿Y la casucha del Beno, el botero?

No quedaba nada, nada más que viento y escombros y silencio y soledad.

Al regresar a Temuco, visité las escuelas 5,7 y 15, que albergaban a los refugiados de Puerto Saavedra. Los Leal no aparecían. Por fin di con un pescador que me dijo que estaban todos a salvo, en Imperial. A ese hombre le pregunté lo que antes había preguntado en Toltén y los Boldos. ¿Pensaban volver al pueblo, tratar de reconstruirlo? La respuesta fue también la misma:

-No, porque el mar se portó mal con nosotros. Nunca más.

Luego agregó:

-Ahora nosotros, los del puerto, nos vamos a tener que separar. ¿No pueden construir una población en alguna parte para poder seguir viviendo juntos? No queremos limosna, queremos trabajo, pero nada que tenga que ver con el mar.

\section{Valdivia, oculta por la niebla}

En Valdivia, fue imposible aterrizar debido al mal tiempo. Llovió desde que se produjo la catástrofe, y cuando no llovía, las nubes bajas impedían la visibilidad. En un momento que las nubes subieron algo, logramos introducirnos y sobrevolar Valdivia unos minutos, casi al ras de las casas y de los árboles. La visión de esos minutos fue de un infierno húmedo. La destrucción fue total. Los pavimentos de adoquines resquebrajados como un puzzle macabro. Enormes grietas llenas de agua reflejan las ruinas. Desaparecieron las avenidas de la ribera, los árboles fueron desarraigados, los seres humanos se aglomeraban en unos cuantos sitios buscando protección. Todo Valdivia se hundió varios metros. El 40 por ciento de las casas fueron destruidas. El 30 por ciento quedaron seriamente dañadas. Cientos de personas desaparecidas. Cientos de muertos.

Llegamos a Osorno a las seis de la tarde del miércoles, con niebla y casi sin luz. En un principio, la ciudad se presentó casi intacta ante mis ojos. Pero al recorrerla lentamente, fui apreciando los daños. En Osorno, construido sobre priora rocosa, no sobre vegas como Valdivia o Concepción, hay sólo casas de madera y edificios modernos, asísmicos. Muchas de las casas de madera se 
habían corrido de sus cimientos; otras cayeron, y gran parte de los edificios nuevos quedaron agrietados. La fundición Volcán se desplomó entera, y los cien obreros que en ella trabajaban, se libraron de la muerte sólo porque era domingo. Parte del hospital también se derrumbó y el resto quedó inutilizado. Será necesario demoler la catedral. La iglesia alemana tiene su gran torre fuera del centro, formando una especie de alero peligroso. Los pobladores temen que los edificios que por fuera parecen normales, al ser examinados presenten grietas interiores.

Esa noche dormí en casa de un compañero de colegio, a quien no veía desde hacía quince años. Tiene cuatro niños. Mientras comíamos, los ojos de sus hijos estaban fijos en la lámpara del comedor, esperando que el menor movimiento delatara la repetición de la catástrofe.

El boletín que La Prensa publica todos los días noticias de desastres en el interior. Llegan también noticias del litoral. Los balnearios de Maicalpi y Pucatrihue, arrasados por el mar. El pequeño puerto de Bahía Mansa, el único de la provincia, cuyo muelle de cien metros estaba recién terminado, también desapareció.

\section{De Osorno a Puerto Montt}

La mañana siguiente amaneció lluviosa, de modo que se hizo imposible continuar a Puerto Montt en avión. La única posibilidad era conseguir que alguien me llevara en auto. Fui a la Intendencia, donde me dijeron que aun por tierra era difícil el viaje, porque la mayor parte de los puentes estaban cortados. Sin embargo, me aposenté junto a la ventanilla donde se daba el permiso de racionamiento de bencina, hasta que alguien que iba a Puerto Montt a buscar a sus padres en un jeep consintió en llevarme. Partimos bajo la lluvia a las doce del día.

Esta tierra joven era nueva para mí, libre de los lastres coloniales de latifundio e inquilinaje. Es una zona rica, potente, libre, que está haciéndose a sí misma. La gente que conocí en Osorno me pareció materialista. Pero en una región que está levantándose, sin tradiciones aún, es natural que así sea. El hombre vale por el número de hectáreas que posee y por la capacidad de su bolsillo, hinchado por el trabajo. No es una región sabia, pero eso vendrá después, cuando haya un descanso para adquirir conciencia. Y este Chile joven, tan distinto al del norte, me mostraba además un rostro de belleza pacífica y conmovedora. Campos de suaves colinas, cubiertas de robles envueltos en su follaje dorado y entre un coigüe verde y algún raulí alzándose escarlata como una copa de vino.

Pero 33 kilómetros al sur de Osorno, todo cambió bruscamente. Atravesamos por un lado el río Chifín, remontamos una colina, y vi lo que quedaba del 
puerto de Río Negro. Nada. Río Negro, posado sobre la vertiente de una colina, parecía haberse deslizado colina abajo. Los dos edificios asísmicos de tres pisos, la gobernación y correos, se desplomaron como si hubieran sido de barro.

La impresión que tuve de Puerto Montt fue doble.

Por un lado, la ciudad devastada. Angelmó, por antonomasia el puerto pintoresco del sur, arrancado de raíz, mostraba apenas el diseño de los cimientos de las casas. El muelle desaparecido, y lo que quedaba, torcido como un débil juguete en las manos de un niño perverso. La población Modelo, recién terminada, destruida por un rodado. Colegios, conventos, estación, pavimentos, todo devorado por el desastre. Un 40 por ciento de las casas por el suelo.

Por otra parte, sin embargo, tuve la impresión de que Puerto Montt no se había abandonado a la tragedia. Es una ciudad de ese sur nuevo y potente, del que tuve una visión en Osorno, aquí en la plenitud de su eficacia para remediar los daños. La esperanza flotaba en el aire. Todo el mundo contribuía al orden y al funcionamiento de Puerto Montt. Patrullas de voluntarios removían escombros. Un niño, con su carretilla de juguete, acarreaba tierra y maderas. Me dijo que se llamaba Andresito, y que estaba ayudando a su padre. Los aviones del norte, chilenos y norteamericanos, aterrizaban sin cesar en La Chamiza y El Tepual, llevando víveres y ropa que se repartían entre la población. Los bomberos, que han hecho un noble papel, patrullaban las calles y ayudaban en todo. La vida privada no existía, ni existían las horas, ni el sueño, ni el cansancio.

Jorge Brahm, el Intendente, señaló:

-Esta zona no ha quedado imposibilitada por la tragedia. Puerto Montt, como centro de abastecimiento de otros puntos, no carece combustible, y el racionamiento de bencina será soltado mañana.

Dentro de algunos días, se contactará la ciudad con la planta de Pilmaiquén, y habrá electricidad. En cuanto a abastecimiento, todo lo necesario fue requisado el primer día. Caritas, mantiene nueve ollas para los necesitados.

Al interrogarlo sobre la rehabilitación de los centros de producción, que deben volver a levantar la economía de la zona, me respondió:

-Los daños de las industrias básicas de Puerto Montt no han sido grandes. Iansa funcionará dentro de seis días. Además comprará toda la producción de remolacha al contado, no a plazos como antes. Las plantas lecheras están casi intactas. Comenzarán a funcionar mañana. Creo que Puerto Montt no tardará más de diez años en levantarse de nuevo, y será una ciudad mejor construida, mejor planeada y más rica que antes.

Esa noche me dediqué a recorrer Puerto Montt. Circulaba el rumor de que hubo quince fusilamientos por pillaje. No logré comprobarlo. Hubo los robos naturales a que conducen las casas abiertas, la falta de ropa y de carbón, pero no más. 
En una escuela donde había más de trescientos refugiados de la población Modelo, hablé con varias personas que dijeron haber sufrido robos. Entre otros, don Manuel de la Barra y su familia. Dice que al huir dejó su casa abierta. Cuando fue a verla más tarde, la encontró sin puertas ni ventanas. Entre los escombros buscó la ropa de su familia, y se dio cuenta de que habían desaparecido una Sindelita, un cajón con ropa, otro con servicio y varias cosas más. Dice que le han robado por un valor de cuatrocientos mil pesos.

Interrogué a Alberto Ebensperger, abogado de Carabineros:

-Es cierto que hubo algunos robos en el primer momento de pánico, pero sólo el mínimo, gente que necesitaba ropa o carbón. En cuanto a los fusilamientos, no es más que un rumor nacido a raíz de que el primer día, dos carabineros encontraron a unos hombres robando, y persiguiéndolos, dispararon unos tiros.

\section{Ancud}

En la Chamiza, esperé hasta las once que llegara mi avión de Osorno. Estaba a punto de encararme en otro cuando lo vi planear sobre el campo. No tardamos ni cinco minutos en partir de nuevo, rumbo a Ancud, por sobre las islas del seno de Reloncaví y del canal de Chacao.

Aterrizamos en Pudeto, a las doce. Anduve un kilómetro para atravesar el río, y en la orilla, me subí al jeep del Prefecto de Carabineros, Miguel Urzúa. El pueblo de Pudeto había sido tragado por el mar. Entre las líneas de los cimientos no vi más que un par de sillas de felpa, con borlas y caireles, coja de una pata, pero en pie aún, señoreando el desastre.

En el barrio La Arena, habitado por pescadores, que circunda en el plano la ciudad construida en cerros, no quedó absolutamente nada. Entre los tablones sueltos, una mujer con ojos alucinados recogía ropa en el mar, en el mismo sitio donde antes estuvo su casa. Había aguardado horas allí, esperando que el mar le devolviera algo, con la vista fija en el horizonte. Sólo ahora, cinco días después del desastre, encontró unos pañales que reconoció como los de su guagua recién nacida.

-Este es el barrio que más sufrió -dijo el prefecto Urzúa-. Muertos oficiales no hay más que treinta y cinco. Pero los desaparecidos suben de los trescientos. Lo más grave no fue el terremoto, sino que la salida del mar, que llegó a cinco metros de la plaza.

El prefecto enmudeció un instante. Luego comenzó a relatar la odisea de la lancha Gloria, que carabineros usaban para patrullar los canales. 
-Sólo en la lancha Gloria desaparecieron cerca de cuarenta -dijo-. Era una linda lancha, rápida, construida en los artilleros de Valdivia. Costó veinte millones de pesos y tenía doce metros de largo. Este domingo, como siempre que la lancha no estaba en uso, quedó un carabinero a su cuidado, José Miguel Vergara. Cuando comenzó a temblar, muchos de los pobladores de La Arena huyeron hacia el mar para embarcarse en sus botes, porque se sienten más seguros en el mar que en la tierra. Entonces comenzó la primera salida del mar, lenta pero amenazadora. Muchos de los pescadores amarraron sus propios botes a la lancha Gloria, para que ésta los arrastrara, y se subieron a ellas con sus familias, y la escasa ropa que tuvieron tiempo para salvar. Después de la primera salida, el mar se replegó hasta la isla de Cochino -esa que usted ve allá, a un kilómetro-, y todo ese kilómetro quedó seco. Esta vez el mar arrastró a la lancha Gloria hasta la isla misma. Yo lo vi todo, porque estaba en el cerro, mirando con los anteojos de larga vista. La bahía entera estaba sin agua. La lancha Gloria encalló en la isla. Hubo unos minutos de calma, en que los que iban a bordo comenzaron a bajarse y a correr de un lado para otro. Veía a los padres -los conocía a todos- sacando a sus chiquillos y cargándolos para arrastrarlos hasta la playa. Entonces, cuando todos estaban en tierra, vi que se formaba una inmensa ola negra que ocupó todo el horizonte. Los de la isla Cochino también la vieron y oyeron su estruendo, porque los vi correr de nuevo hasta la lancha para tratar de subirse. Pero no tuvieron tiempo, porque la ola inmensa y rugiente los arrastró, y todos desaparecieron.

En el silencio que siguió al relato del prefecto Urzúa, no puedo dejar de recordar a esa población de chilotes emigrados en Argentina, con los que, en torno a unas copas de grappa o de ginebra, conversé en Comodoro Rivadavia y en Río Gallegos. Estos hombres rudos, resistentes a cualquier inclemencia, hablaban con los ojos llenos de lágrimas, de Ancud, Castro y Chonchi, como quien habla del paraíso terrenal. Mientras más grappa tomaban, más hermoso aparecía Chiloé en sus relatos, hasta que los argentinos quedaban convencidos que la isla es un Eldorado. ¿Dónde están esos chilotes errantes ahora? ¿Cuántos perdieron la vida en la lancha Gloria, sepultando en el mar la razón de sus nostalgias y lealtades?

Visitamos en seguida la población de la Corvi, construida en los cerros, destinada a albergar ochenta familias y que se halla inconclusa, pero con techos y vidrios. En ella viven ahora dos mil refugiados del barrio La Arena, a cargo de la visitadora social Laura Elgueta de Barrientos:

-El mayor problema del momento es la falta de letrinas, porque esto puede dar origen a una epidemia de tifus. Estamos vacunando a los dos mil habitantes para defendernos de la posibilidad, que sería desastrosa. 


\section{El cataclismo de Tranguil}

De regreso, pasamos junto al volcán Puyehue, en plena erupción. Una inmensa nube blanca, se elevaba hasta perderse en el azul del cielo, reflejándose en el lago como una tracción salvajemente irónica para el turista. Desde el avión, todo era tranquilo. En el día transparente, una vela blanca surcaba el lago, como si nada ocurriera. Pero la nube estaba allí, inmensa y poderosa, como un puño ferozmente amenazador.

Ese sábado, que debía ser el último de mi viaje, dejamos atrás Villarrica, Calafquén, Pellaifa, y nos fuimos internando cordillera adentro. Nos metimos por un desfiladero, y se abrieron nuevos valles, nuevos lagos, nuevos ríos ante mi vista, hasta llegar a la localidad de Liquiñe, donde había una cancha de aterrizaje.

Al descender del avión, nos acogió un círculo de rostros sonambulescos, mudos, aterrados. Las facciones eran todas indígenas, casi iguales, de pómulos altos y de ojos clavados por el pavor. De vez en cuando alzaban la vista hacia el apretado anfiteatro de montañas boscosas que nos rodeaba como esperando otro de los sesenta derrumbes ocurridos en la localidad. Uno de los rodados, el de Malihue, cerró en un trecho de ocho kilómetros, el camino que comunicaba el pueblo de Villarrica, a ochenta kilómetros de distancia, dejando a la población totalmente aislada. ¿Qué se podía hacer contra los dos cerros de Malihue que al derrumbarse dejaron a la población presa del viaje?

El peor de todos los rodados fue el de Tranguil, que no causó heridos, sino que dejó cerca de noventa muertos en una región de dos kilómetros. Hablé con Juan Antonio Luengo, colono de Tranguil. Estaba sumido en un gran silencio, un silencio en que estaba escrita la pérdida de todo: mujer, hijos, y bienes, con una elocuencia desgarradora. Él había quedado con vida por un milagro, ya que andaba en el pueblo haciendo trámites. Le costó comenzar a hablar, como si tuviera que romper la barrera para hacerlo, y dijo que en la zona de Tranguil había cerca de diez familias de colonos con sus casas.

Quise ir a Tranguil, pero me dijeron que era preferible no hacerlo, puesto que los derrumbes continuaban, y que la tierra temblaba y se agrietaba aún. Sin embargo, convencí a Juan Antonio Luengo y a Julián García, dueño de un auto, industrial de la madera y propietario de barracas, que me llevaran. Después de un trayecto de varios kilómetros en auto, tuvimos que dejarlo y proseguir a caballo, atravesando bosques, ríos y pantanos. Más allá dejamos el caballo, porque sólo era posible seguir a pie. Al salir de un bosque, se abrió ante mis ojos el desastre producido por el cataclismo de Tranguil. 


\section{Traición terrestre}

Es el cuadro más desolador que jamás he visto. A dos kilómetros de distancia, se alzaba un cerro cubierto de bosques, pero con una carie roja de dos kilómetros de alto en la vertiente norte. Ese fue el trozo de cerro que se desplomó, tapando el río Rihueco, formando una especie de pantano en cuyo confín estábamos. Los enormes troncos molidos, las enormes rocas pulverizadas, los restos de casas, de cercos, de animales, flotaban en una masa pesada como un mar de esqueletos. Dos kilómetros de cerro desplomado, que arrasaron dos kilómetros de valle, pulverizándolo todo a su paso. En el valle entero, no quedaba más que un solo tronco en pie, negro, despojado de su follaje, solitario como Juan Antonio Luengo, que se paró junto a él. Luengo señaló el derrumbe, y se quedó inmóvil:

-Todo se fue -dijo-. Yo acababa de terminar de construir mi casa. Tenía 45 hectáreas y estaba tramitando los títulos. Por eso fui al pueblo y por eso me salvé. Pero mi mujer y mi hija murieron. Esta es la "corrida" más grande. Yo subía hasta ella. Hay una grieta que la recorre de arriba abajo, y no se le ve el fondo. En algunas partes sale un agua caliente y lechosa, con olor a azufre.

Me quedé en silencio contemplando el desastre geológico que veía. Hasta los pájaros habían huido. La tierra había traicionado la confianza de Juan Antonio Luengo. Fue en los ojos de este colono de Tranguil donde vi reflejada la plenitud de la catástrofe. Vi a los pescadores de Toltén y a los náufragos del Gloria, y a las Sacramentinas de Concepción. Todos me miraban con los mismos ojos de Juan Antonio Luengo, con esos ojos fijos, serios, secos, que contemplaban los kilómetros de desolación, entre cuyos árboles destrozados, quien sabe dónde, se hallaba el cadáver de su mujer y de su hija, y los restos pulverizados de sus haberes.

El regreso fue presuroso y en silencio. No había nada que decir. Esos hombres de manta y rostro sombrío, llamados Catrilaf, Nancuñán, Chihaicura, Pichumilla, sentían el mismo miedo que yo, porque yo tampoco comprendía. Yo era uno de ellos, un ser pequeño en un mundo enorme, que no ofrecía explicación de la vida ni de la muerte. ¿Por qué? ¿Por qué? ¿Era acaso el fin del mundo? Para Juan Antonio Luengo lo fue, con el dolor de permanecer vivo para presenciarlo.

Liquiñe y la región del río Rihueico quedaron aisladas de la civilización por los derrumbes de Malihue. No existe más que una cancha de aterrizaje de trescientos metros, de modo que es imposible que aterricen acciones grandes. El sábado calculaban que la comida no alcanzaría más que para cuatro días si no hacía algo rápidamente. Entonces comenzaría la hambruna.

Pregunté a Julián García por qué había cancha de aterrizaje en Liquiñe:

-Es improvisada. Pasamos todo el día 21 aislados, tratando de contener nuestro pánico. Esa noche fue terrible, con el terror de que los cerros continuaran 
desplomándose sobre nosotros. El lunes, cerca de las once, divisamos un avión. Uno de los habitantes de Liquiñe, Hans Plageman, se dio cuenta que era el de su primo Villarrica, Egon Bernkhoff. Entonces, toda la población se lanzó al campo, agitando sábanas y pañuelos hacia ese avión, que era toda nuestra esperanza. Los hombres arrancaron cercas y botaron muros de madera para improvisar una pista de aterrizaje. El avión finalmente descendió, y llevó noticias de nuestro desastre al mundo. Cuando el avión partió nos pusimos a aplanar la cancha, para recibir la ayuda aérea que Berkhoff nos prometió. Puedo decir que el club aéreo de Villarrica nos ha salvado la vida, porque con los tres aviones que tienen, nos están trayendo víveres constantemente. El agradecimiento de esta zona para con el club aéreo de Villarrica, será eterno.

Plageman y García son los principales industriales de la región, y ven el problema desde su punto de vista. Para ellos es absolutamente necesario que el Estado o bancos particulares les concedan créditos a largo plazo para adquirir la madera de los colonos y almacenarla hasta que sea posible sacarla de la región. Si no hay compra de madera, los colonos no comerán y la región se vendrá abajo. Como todos, Plageman y García no quieren caridad, quieren trabajo.

Yo no sé si esta gente podrá volver a trabajar. Hay demasiado terror en esos ojos de indio, demasiada incomprensión de un fenómeno que su cosmología supersticiosa no puede aclarar. Los valles de Malihue, Tranguil, Rihueico y Liquiñe han quedado poblados de seres fantasmales, incapaces de sentir otra cosa que miedo ante lo que les es totalmente inexplicable.

Donoso, José. Desde el margen; a la búsqueda de los pueblos desaparecidos. En su: El escribidor intruso. Santiago de Chile, Ediciones Universidad Diego Portales, 2007. 307-320 pp. 